\title{
Robot Kapal Selam Pendeteksi Keberadaan Benda
}

\author{
Dessyana Kardha*1, Budhi Sumboro $^{2}$, Yunius Arsita ${ }^{3}$ \\ ${ }^{1,3}$ Program Studi Sistem Komputer, STMIK AUB, Surakarta, Indonesia \\ ${ }^{2}$ Program Studi Sistem Informasi, STMIK AUB, Surakarta, Indonesia \\ e-mail: *1 dessyanakardha@stmik-aub.ac.id, ${ }^{2}$ budhi.sumboro@stmik-aub.ac.id, \\ ${ }^{3}$ yuniusar11@gmail.com
}

\begin{abstract}
Abstrak
The current technological developments so rapidly, as well as the development of electronics technology. Robotics is a proof of human civilization that progresses from time to time. The shape of the robot is not just a form that resembles a human or a certain animal, but moves to resemble the form it imitates. The development of computer technology associated with other devices. The problem of this research is the difficulty of checking leakage of gas or water pipes in the pond. The main purpose of the research is to design and build a complete submarine robot with an endoscope camera that can replace human power for. How this robot works is a robot moving forward, backward, turn right, turn left, move up and down (dive) and equipped with a camera to detect the existence of an object. This robot combines hardware and software, using Arduino Uno Microcontroller as the controller of robots, cameras, and motor drivers as control of propeller motion. The submarine is equipped with an endoscope camera as a leak detector of gas or water pipes inside the pool, especially the detection of objects. The result of the research is a robot can dive in the water base to detect the presence of objects. From this then the authors make a robot submarine detection of the existence of objects that can replace human power to check the leakage of gas or water pipes in the pool. expected robots can be smarter than the previous one.
\end{abstract}

Kata kunci: Detecting the Presence of Objects, Cameras, Arduino Uno, Microntrolers

\section{PENDAHULUAN}

Perkembangan teknologi saat ini begitu pesat, demikian pula dengan perkembangan teknologi elektronika. Robotika merupakan bukti peradaban manusia yang semakin maju dari waktu ke waktu. Wujud robot bukan hanya sebuah bentuk yang menyerupai manusia atau binatang tertentu, melainkan bergerak menyerupai bentuk yang ditirunya.

Kata "robot" diambil dari Bahasa Ceko (Chech) yang memiliki arti " pekerja" (worker). Robot merupakan suatu perangkat mekanik yang mampu menjalankan tugas-tugas fisik, baik di bawah kendali dan pengawasa manusia, ataupun yang dijalankan dengan serangkaian program yang telah didefinsikan terlebih dahulu atau kecerdasan buatan (artificial intelligence).

Jika sebelumnya robot hanya dioperasikan di laboratorium ataupun dimanfaatkan untuk kepentingan industri, di negara-negara maju perkembangan robot mengalami peningkatan yang tajam. Seiring dengan berkembangnya teknologi, khususnya tidak saja di bidang sains, tetapi juga di berbagai bidang lainnya, seperti di bidang kedokteran, pertanian, bahkan militer. Secara sadar atau tidak, saat ini robot telah masuk dalam kehidupan manusia sehari-hari dalam berbagai bentuk dan jenis. Ada jenis robot sederhana yang dirancang khusus untuk melakukan sesuatu yang rumit, sehigga dapat berperilaku sangat kompleks dan secara otomatis dapat mengontrol dirinya sendiri sampai sampai batas tertentu.

Received May 6, 2019; Revised May 27, 2019; Accepted June 12, 2019 
Menurut buku The Robot Builder's Bonanza yang ditulis oleh Gordon McComb secara umum robot dapat didefinisikan sebagai sebuah piranti mekanik yang mampu melakukan pekerjaan manusia atau berperilaku seperti manusia. Salah satu pekerjaan manusia yang dapat dilakukan robot adalah kegiatan menyelam dan mendeteksi keberadaan benda. Jenis pekerjaan ini membutuhkan reaksi cepat karena kamera yang terpasang pada robot dapat mendeteksi keberadaan benda. Robot kapal selam sendiri dapat di implementasikan pada dasar permukaan air yang akan di cek, ada apa saja di dalam dasar permukaan air tersebut. Suatu misal kolam yang terdapat saluran pipa gas atau pipa air yang bocor maka kamera dapat mendeteksi lubang pada pipa tanpa harus manusia yang langsung melakukan kegiatan menyelam, jika robot kapal selam sudah teruji dapat mendeteksi kebocoran pipa maka robot kapal selam dapat mendeteksi keberadaan benda yang terdapat pada dasar permukaan air kolam yang jernih. Atau pada embung atau tandon air di berbagai daerah dapat di ketahui ada apa saja di dalam permukaan airnya pada tingkat kejernihan tertentu dan batas jarak selam $3 \mathrm{~m}$ karna terbatasnya kabel daya dan kamera endoskop, supaya kamera pada kapal selam dapat mendeteksi benda apa saja dalam embung tersebut. dengan adanya robot kapal selam ini maka dengan tahap pengembangan robot kapal selam dapat mengatasi keluhan manusia dalam menangani kebocoran pipa dalam kolam dan mendeteksi ada benda apa saja didalam kolam pada tingkat kejernihan tertentu. Pada sisi kanan, kiri dan bawah kapal selam terdapat motor DC yang berfungsi sebagai penggerak kapal selam. Jika motor sebelah kanan hidup maka kapal selam berbelok ke kiri sedangkan jika motor sebelah kiri hidup maka kapal selam berbelok ke kanan lalu jika kedua motor kanan dan kiri hidup maka kapal selam bergerak maju dan jika motor bagian bawah hidup maka kapal selam menyelam. Dengan bantuan motor DC maka pergerakan kapal dapat di atur dengan baik.

Berawal dari permasalahan tersebut, maka pada penelitian ini peneliti akan mencoba melakukan penelitian robot Kapal Selam yang dengan berjudul "ROBOT KAPAL SELAM PENDETEKSI KEBERADAAN BENDA".

\section{METODE PENELITIAN}

\subsection{Jenis Data}

a. Jenis dan Sumber Data

1) Jenis Data

Pengetahuan yang didapatkan dari pengamatan atau penelitian suatu objek tertentu (Moh Natsir: 2005). Jenis-jenis data dibagi berdasarkan sifat dan sumbernya. Menurut sifanya, jenis-jenis data yaitu :

a. Data kualitatif adalah data yang tidak berbentuk angka.

b. Data kuantitatif adalah data yang berbentuk angka.

Jenis-jenis data menurut sumbernya, antara lain:

a. Data internal adalah data dari dalam suatu objek yang menggambarkan keadaan objek tersebut.

b. Data eksternal adalah data dari luar suatu objek yang dapat menggambarkan faktorfaktor mempengaruhi suatu objek (Moh.Nazir, 2005).

2) Sumber Data

Sumber data penelitian merupakan data yang diperoleh dari sumber yang berkaitan dengan penelitian yang sedang dilakukan. Sumber data penelitian dibedakan menjadi dua, yaitu sumber data primer dan sumber data sekunder.

a. Data Primer

Data primer adalah sumber data yang langsung memberikan data kepada pengumpul data. Pengumpulan data primer dalam penelitian ini dengan cara melakukan wawancara secara langsung dengan pihak-pihak yang berhubungan dengan penelitian yang dilakukan (Sugiyono, 2012). Untuk memperoleh data primer peneliti melakukan wawancara kepada Sarjuni Adi Saputro dan Slamet Subagiyo, Galang untuk mengetahui bagaimana cara merancang dan membangun robot kapal selam.

b. Data Sekunder

GO INFOTECH: JURNAL ILMIAH STMIK AUB Vol. 25, No. 1, Juni 2019 : 53 - 61 
Data sekunder adalah sumber yang tidak langsung memberikan data kepada pengumpul data, misalnya lewat orang lain atau lewat dokumen atau dengan media lain yang berkaitan dengan penelitian (Sugiyono, 2012). Untuk memperoleh data sekunder peneliti mencari dan mengumpulkan buku tentang robotika, laporan penelitian terdahulu serta berbagai jurnal tentang robotika terutama tentang robot kapal selam baik nasional maupun internasional.

2.2. Teknik Pengumpulan Data

a. Observasi

Metode Observasi adalah cara pengambilan data dengan menggunakan mata tanpa pertolongan alat standar lain untuk keperluan tersebut, metode observasi dilakukan dengan cara mengumpulkan data dimana peneliti mengadakan pengamatan menyeluruh. (Moh.Nazir: 2005) Pada metode ini peneliti melakukan pengamatan terhadap robot kapal selam yang sudah ada serta membandingkan kelemahan dan kelebihan masingmasing robot kapal selam agar robot yang dibuat oleh peneliti lebih baik dari robot kapal selam yang sudah ada.

b. Wawancara

Metode studi pustaka merupakan adalah suatu metode pengumpulan data dengan cara membaca atau mempelajari buku-buku refrensi yang berhubungan dengan masalah yang akan dibahas guna memperoleh landasan teori untuk keperluan menganalisi data, tujuan dari studi pustaka adalah untuk memperoleh referensi yang dibutuhkan dalam proses pengerjaan metode untuk menyelesaikan penelitian (Moh.Nazir: 2005). Pada metode ini peneliti melakukan wawancara kepada Sarjuni Adi Saputro, Galang Budi Sanjaya, dan Slamet Subagiyo tentang bagaimana merancangan dan membuat robot kapal selam.

c. Studi Pustaka

Metode Wawancara Metode wawancara adalah proses memperoleh keterangan untuk tujuan penelitian dengan cara tanya jawab, sambil bertatap muka antara si penanya atau pewawancara dengan si penjawab atau responden dengan menggunakan alat yang dimanakan interview guide, metode wawancara ini dilakukan bertemu langsung dengan orang yang bersangkutan (Moh.Nazir: 2005).

\section{HASIL DAN PEMBAHASAN}

\subsection{Perakitan Alat}

Didalam proses perakitan alat, dimulai dengan menyiapkan sketsa rancangan dengan tujuan agar tidak menggunakan papan PCB berlebih, membuat alat lebih minimalis ringkas bentuknya, dan agar tidak terjadi kesalahan yang fatal ketika perakitan alat. Merangkai dan menyolder seluruh komponen elektronika yang telah disiapkan antara lain mikrokontroler Arduino Uno, driver motor, kabel jumper dan komponen lain pada papan PCB dan mika. Saat perakitan komponen, terlebih dahulu memanaskan solder untuk meleburkan tenol. Langkah penyolderan dilakukan harus dengan bersih, teliti, rapi, dan hati- hati sesuai dengan gambar skema rangkaian.

\subsection{Perakitan Power Supply}

Power supply adalah sistem elektrik untuk mendistribusikan daya listrik agar kinerja robot optimal. Dalam perakitan power supply ini penulis memilih power supply. Power supplay ini akan disambung dengan arduino melalui kabel jack konektornya tipe DC untuk sistem minimum Arduino Uno. Untuk merancang sistem distribusi arus DC diperlukan tamabahan alat terminasi tambahan agar sumber arus bisa disebat ke komponen- komponen robot. Terminal pin power supply pada sistem minimum Arduino Uno sendiri terbatas. Power supply mengisi daya ke sistem minimum Arduino uno agar daya disebar ke seluruh rangkaian lainnya. 


\subsection{Pendeteksi Benda}

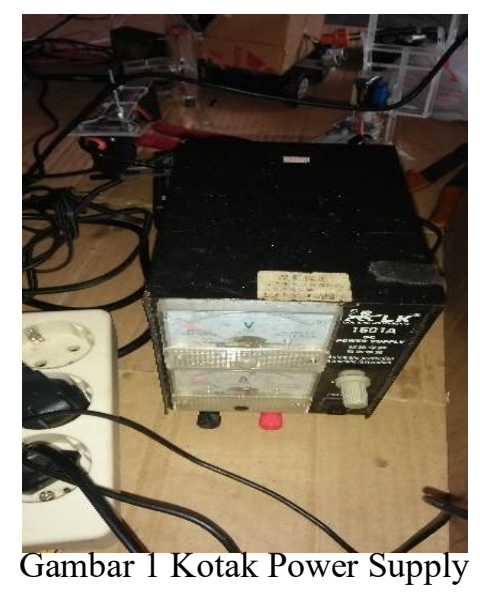

Pendeteksi benda adalah sistem elektrik untuk mendeteksi adanya benda di kolam yang akan dilalui robot. Prinsip kerja deteksi benda ini adalah melihat kolam yang akan dilalui melalui kamera. Pengguna mengetahui adanya benda yang terdeteksi atau terlihat dan mengarahkan robot menggunakan remote.

Dalam perakitan pendeteksi benda ini penulis menggunakan kamera endoskop yang di koneksikan dengan handphone. Dengan demikian pengguna dapat mengetahui kapan berhenti untuk menghindari halangan atau mengetahui adanya benda di depan robot.

\subsection{Penggerak Robot}

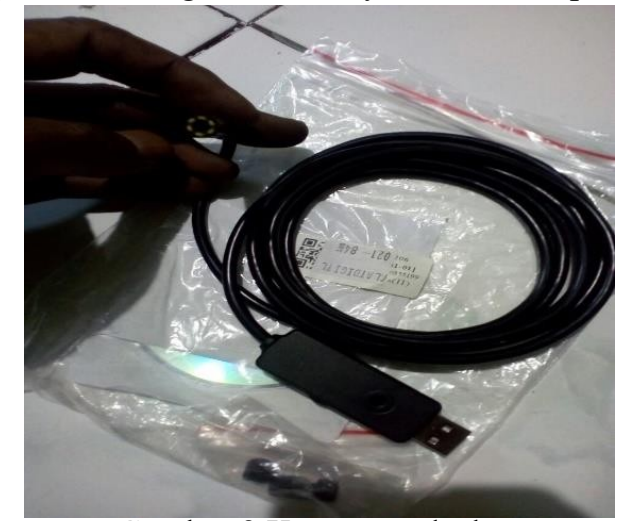

Gambar 2 Kamera endoskop

Penggerak robot adalah sistem elektrik penggerak utama ( motor driver) pada robot agar robot bisa bergerak maju, mundur, belok sesuai dengan program logika. Prinsip kerja penggerak robot ini adalah menggunakan shield motor (drive) dan motor DC. Shield motor berfungsi sebagai pengendali kecepatan dan arah putar maju atau mundur. Motor DC sebagai motor penggerak utama dan baling robot.

Dalam perakitan penggerak motor utama ini penulis menggunakan dua motor DC yang sudah dilengkapi dengan kipas baling-baling sehingga torsi yang dihasilkan cukup untuk melakukan pergerakan robot kapal selam. 


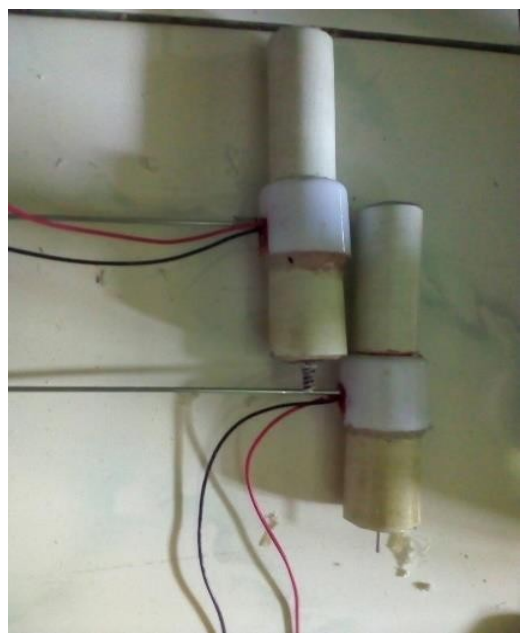

Gambar 3 penggerak motor DC yang di bungkus dalam pipa.

\subsection{Perakitan Kendali Motor (Driver Motor)}

Motor listrik digunakan sebagai penggerak agar robot dapat berjalan maju dengan menggunakan tipe L293D. Hasil penyolderan dari driver motor dapat dilihat pada gambar 4.

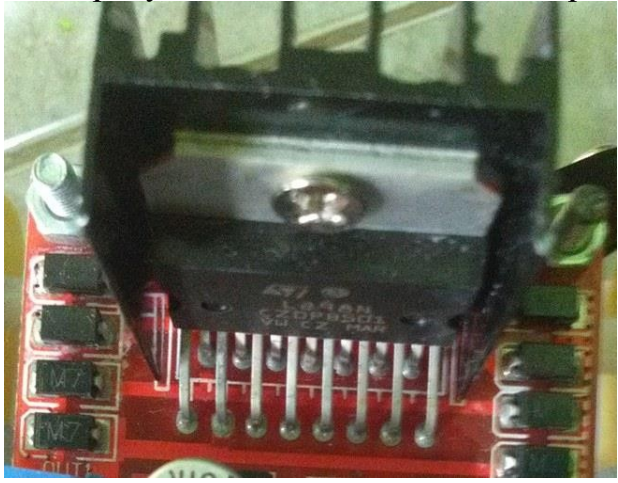

Gambar 4 Hasil Penyolderan Kendali Motor (Driver Motor)

Penjelasan gambar 4 adalah didalam L293D terdapat Pin Enable EN 1.2 \& EN3.4, Pin Input (1A, 2A, 3A, 4A) d. Pin Output (1Y, 2Y, 3Y, 4Y). Pin VCC (VCC1,VCC2) masing-masing pind disolder didalam skema yang sudah disediakan, siapkan tenol dan solder. Masukan ujung pin kedalam lubang skema yg sudah disediakan, solder dengan menggunakan tenol, lakukan dengan hati-hati dan amati secara detail apakah komponen sudah benar-benar terpasang L293D berfungsi sebagai penggerak (driver) yang terhubung ke motor listrik. Dua buah motor listrik digunakan agar robot dapat bergerak maju. Jika kecepatan putar dari kedua motor listrik sama maka robot bergerak lurus dan jika kecepatan putar dari kedua motor listrik berbeda maka robot bergerak membelok.

\subsection{Perakitan Mikrokontroler Arduino Uno}

Pada gambar 5 perakitan komponen pin mikrokontroler Arduino Uno dilakukan secara cermat dan hati-hati dimana mikronkontroler ini memiliki 14 pin digital input dan output. 


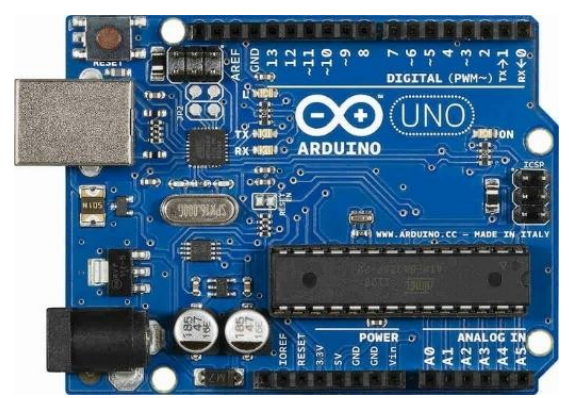

Gambar 5 mikrokontroler Arduino Uno

Perakitan dilakukan dengan terlebih dahulu memasang mur dan baut dudukan mikrokontroler pada papan akrilik. Karena banyaknya pin itulah pemasangan harus dilakukan dengan teliti dan hati-hati agar tidak terjadi konsleting pada arduino antara pin satu dengan yang lain. Masing masing pin akan dihubungkan ke terminal, sumber daya, dan driver motor, Pin Power $(5 \mathrm{v}, \mathrm{Gnd})$ dan Pin Input $(0,1)$ akan dihubung kan ke socket female yang terhubung dengan sensor ultrasonik. Pin Power $(9 \mathrm{v}, \mathrm{Gnd})$ akan dihubungkan ke dalam Batrei 9Volt sebagai sumber tenaga, Pin Input $(1,2,3,4,10,11)$ akan dihubungkan ke Driver motor sebagai penggerak. Semua pin tersebut dihubungkan dengan menggunakan kabel jumper yang berwarna-warni tersebut. 3.8 Perakitan Keselurahn Komponen

Perakitan keseluruhan komponen dilakukan dengan sangat hati-hati dan berusaha agar tenol antara satu jalur dengan jalur lain tidak menyambung. Perakitan dilakukan dengan rapi, dan berjarak dekat agar tidak terlalu memakan ruang yang lebar saat dipasang pada objek. Berikut adalah gambar 6 dari perakitan keseluruhan komponen:

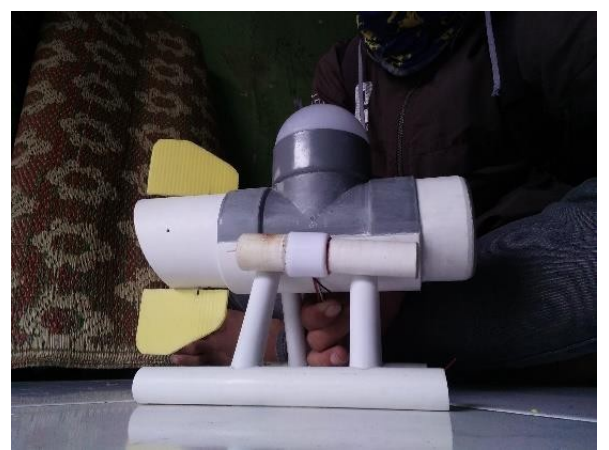

Gambar 6 Hasil Keseluruhan Robot Kapal Selam

Hasil dari perakitan dari seluruh komponen bisa disimpulkan bahwa tombol power terdapat pada kapal dibagian tertentu yang kedap air untuk menghidupkan robot lalu bluetooth pairing terlebih dahulu setelah conect baru robot kapal selam bisa di jalankan. Kamera juga otomatis merekam setelah smart phone terconect dengan kamera endoskop dan hasilnya dapat di lihat dalam layar smartphone tersebut. Pada bagian dalam kapal yang berwarna biru terdapat rangkaian mikrokontroler Arduino Uno sebagai pengendali robot. Driver motor terdapat pada bagian samping mikrokontroler Arduino Uno yang berwarna merah sebagai pengendali gerak motor. Kabel jumper berwana hijau,biru,ungu,abu pada terminal yang terhubung ke sistem minimum Arduino Uno berfungsi sebagai inputan dan masukan sinyal bluetooth yang akan diolah melalui mikrokontroler Arduino Uno, Kabel berwana jumper hijau,biru,ungu,abu pada sistem minimum yang berada didepan dihubungkan dengan driver motor sebagai perintah untuk memberikan sinyal kepada driver motor supaya dapat diolah dan menjalankan perintah bergeraknya baling-baling, sedangkan kabel driver motor yang berwarna hitam dan merah menghubungkan ke motor DC untuk menggerakkan baling-baling.

3.9 Hasil Menu Remote Arduino RC

GO INFOTECH: JURNAL ILMIAH STMIK AUB Vol. 25, No. 1, Juni 2019 : 53 - 61 
Tampilan ini adalah menu piihan untuk mengaktifkan remote smartphone yang akan digunakan untuk menjalankan robot kapal selam. Tampilan menu remote dapat dilihat pada gambar 7:

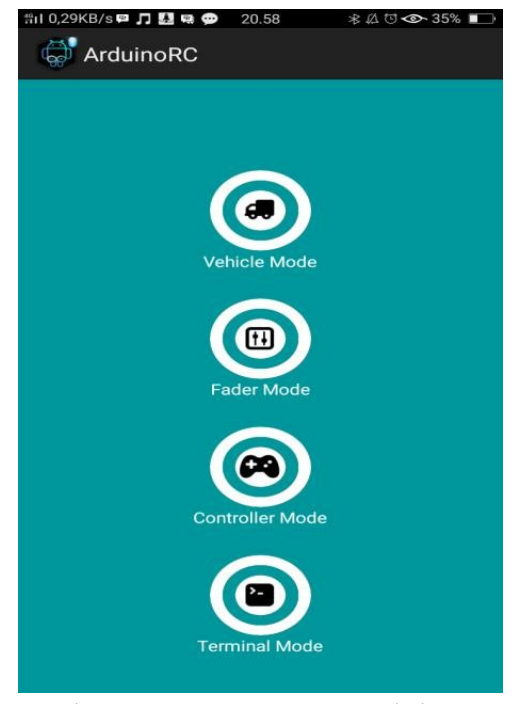

Gambar 7 Menu remote Arduino RC

Tampilan ini adalah tampian remote sebagai penggerak atau pemberi perintah pada kapal selam untuk bergerak kekanan, kiri, maju dan menyelam. Tampilan terminal mode dapat dilihat pada gambar 8:

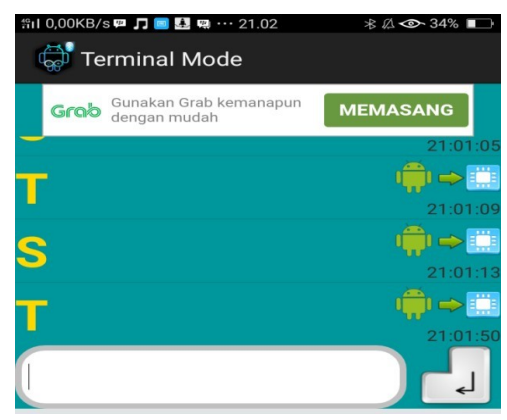

Gambar 8 Tampilan terminal mode

\subsection{Pembahasan Motor 1, 2 dan 3}

Motor 1 dan 2 adalah motor yang berfungsi untuk menggerakkan robot kapal selam untuk maju. Namun jika motor 1 (kanan) hidup dan motor 2 (kiri) mati maka robot kapal selam berbelok ke kiri tetapi jika motor 2 (kiri) hidup dan motor 1 (kanan) mati maka robot kapal selam berbelok ke kanan. motor 1 dapat dilihat pada gambar 9 (a) dan motor 2 dapat dilihat pada gambar 9 (b): 


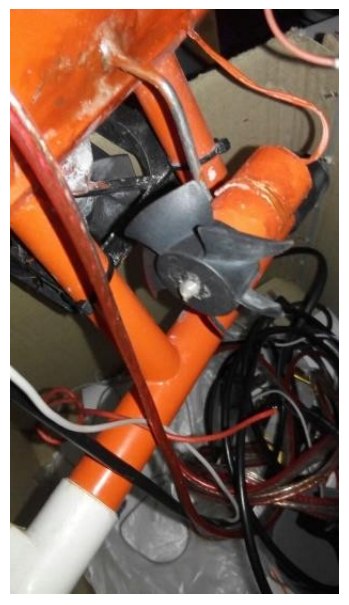

Gambar 9 (a) Motor 1

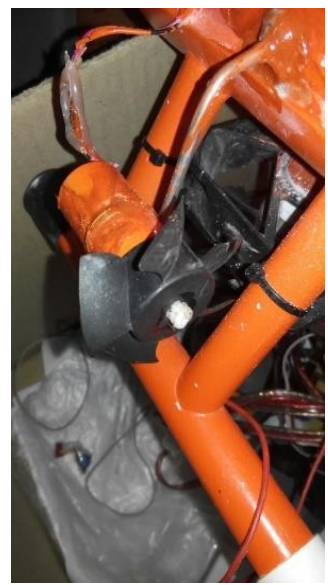

Gambar 9 (b) Motor 2

Motor 3 (bawah) berfungsi untuk menggerakkan robot menyelam dan naik. Jika motor 3 (bawah) hidup maka robot kapal selam menyelam dan jika motor 3 (bawah) mati maka robot kapal selam akan naik dengan sendrinya. Motor 3 dapat dilihat pada gambar 10:

\subsection{Pengujian Alat}

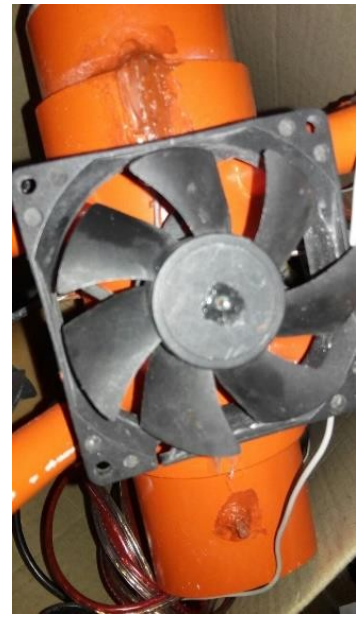

Gambar 10 Motor 3

Adapun pengujian alat adalah sebagai berikut :

a. Pengujian Motor DC

Mengetahui motor DC berfungsi atau tidak yaitu dengan cara memberi arus pada motor DC, jika berfungsi maka baling-baling berputar. Pada robot kapal selam ini terdapat 3 motor yaitu motor 1,2 dan 3 yang memiliki fungsi masing- masing. motor 1 (kanan) hidup dan motor 2 (kiri) mati maka robot kapal selam berbelok ke kiri tetapi jika motor 2 (kiri) hidup dan motor 1 (kanan) mati maka robot kapal selam berbelok ke kanan dan fungsi dari motor 3 yaitu untuk bergerak menyelam dan naik. Jika motor 3 (bawah) hidup maka robot kapal selam menyelam jika motor 3 (bawah) mati maka robot kapal selam naik.

b. Pengujian Kamera

Instal terlebih dahulu instalan bawaan kamera endoskop yaitu software ViewPlayCap lalu di hubungkan antara kamera endoskop dengan laptop. Jika tampil pada laptop maka kamera endoskop berfungsi.

c. Pengujian bluetooth $\mathrm{HC}-05$

Hubungkan bluetooth HC-05 dengan software ArduinoRC yang telah terinstal pada Smartphone yang berfungsi sebagai remote robot kapal selam Lalu tunggu pairing hingga 
terkoneksi, jika HC-05 terdeteksi oleh smartphone yang terinstal software ArduinoRC dan lampu indikator pada Bluetooth $\mathrm{HC}-05$ berkedip pelan maka Bluetooth $\mathrm{HC}-05$ berfungsi .

\section{KESIMPULAN}

Berdasarkan dari hasil perancangan dan pengujian alat, maka dapat ditarik kesimpulan sebagai berikut:Dari hasil perancangan dan implementasi robot yang dibuat menggunakan alat Mikrokontroler Arduino dan Driver Motor ini mampu mengatur dan menjalankan laju dan pergerakan robot kapal selam. Dari hasil pengamatan robot yang dibuat dapat digunakan sebagai prototype untuk menyelam dalam air sebagai alat pendeteksi benda.

\section{SARAN}

Robot yang telah dibuat adalah jauh dari kesempurnaan dan untuk memberikan kesempurnaan maka perlu adanya pengembangan lebih lanjut, antara lain: Untuk pengembangan lebih lanjut robot dapat menggunakan jenis Mikrokontroler yang lain yang lebih canggih dan menggunakan jenis kamera lain selain kamera indoscope. Untuk pengembangan lebih lanjut dapat menambahkan sensor penghalang agar robot dapat bergerak secara mudah dan menghindari halangan lebih dari satu sisi halangan. Menggunakan kamera yang sensitif dan peka untuk menemukan benda di air yang keruh. Melawan arus dengan motor DC yang lebih kuat. Jangkauan remote yang lebih luas. Menggantikan power supply dengan baterai yang lebih kuat.

\section{DAFTAR PUSTAKA}

[1] Arifianto, 2011, Belajar Dasar Elektronika. Yogyakarta: Gava Media.

[2] Banzi, Massimo. 2008. Getting Started With Arduino. USA : O'Reilly Media, Inc.

[3] Dian, Artanto. 2008. Interaksi Arduino dan lab VIEW, Jakarta: Elex Media Komputindo.

[4] Http://arduino.cc/en/Main/Software. https://www.jakartanotebook.com/kamera-usbendoscope-baroscope-black http://www.komitmen.org/2016/11/RemotelyOperatedVeh icles_10.html

[5] Https://id.wikipedia.org/wiki/kapal_selam https://id.wikipedia.org/wiki/Purwarupa

[6] Jogiyanto, 1990. Analisis dan Desain Sistem Informasi,Yogyakarta : Andi Offset.

[7] Made Santo Gitakarma, Ketut Adi Ariawan, Nyoman Arya Wigraha, 2014. Alat Bantu Survey Bawah Air Menggunakan Amoba, Robot Berbasis ROV. Bali: Jurusan Pendidikan Elektro, Jurusan Pendidikan Teknik Mesin, Fakultas Teknik Dan Kejuruan Undiksha, Singaraja.

[8] Muhammad Syukron. 2016. Rancang Bangun ROV (Remotely Operated Vachile) Kapal Selam Berbasis Microcontroller Sebagai Alat Untuk Mengambil Sample Air Dan Tanah Yang Tercemar Limbah. Malang: Jurusan Informatika Teknik Universitas Muhammadiyah Malang.

[9] Salman. 2009 . Sejarah dan Perkembangan Robot, Bandung : SukaRobot.

[10] Siddiq, Asep Jafar 2012. REKAYASA PERANGKAT LUNAK. Yogyakarta: C.V ANDI OFFSET.

[11] Rusmadi, Dedy. 1995. Mengenal Komponen Elektronika. Bandung: Pionir Jaya.

[12] Wirawan Sumbodo. (2008). Teknik Produksi Mesin Industri. Jakarta: Direktorat Pembinaan Sekolah Menengah Kejuruan.

[13] Yanuar Chandra, Didik Setyo Purnomo, Endah Suryawati N. 2016. Rancang Bangun Sistem Ballast Pada ROV (Remotely Underwater Vechile). Surabaya: Politeknik Elektronika Negri Surabaya Institut Teknologi Sepuluh November (ITS) Surabaya Kampus PENS-ITS, Keputih, Sukolilo, Surabaya.

[14] Zuhal. 1988. Dasar Teknik Tenaga Listrik dan Elektronika Daya. Jakarta: Gramedia. 